\title{
Juglone can inhibit angiogenesis and metastasis in pancreatic cancer cells by targeting Wnt/ $\beta$-catenin signaling
}

\author{
Gokturk F, Erkoc-Kaya D, Arikoglu H \\ Selcuk University, Faculty of Medicine, Department of Medical Biology, Konya, Turkey. \\ cebesoyfatma@gmail.com
}

\begin{abstract}
OBJECTIVES: We aimed to investigate the effects of juglone on angiogenesis, metastasis and cell proliferation processes in pancreatic cancer $(\mathrm{PC})$ and to understand whether its possible effects occur via the Wnt signaling pathway by analyzing the expression levels of target genes of Wnt signaling.

BACKGROUND: PC is a silent and lethal cancer type which can only be detectable after metastasis and angiogenesis processes occured. The Wnt signaling pathway is one of the pathways that plays an active role in many biological processes in the cell. Mutations in the genes of this signaling pathway are related to the development of many cancers. Juglone, a natural compound, is shown to have cytotoxic and apoptotic effects on various cancer cells.

METHODS: PANC-1 and BXPC-3 pancreatic cancer cells were treated with juglone at $<$ IC50 doses $(5,10$, 15 , and $20 \mu \mathrm{M}$ ) for $24 \mathrm{~h}$. Expression levels of MMP7, VEGF, TCF7L2, CCND1 genes were determined by RT-PCR. Cell migration evaluation after juglone treatments were done by a wound-healing assay.

RESULTS: Juglone seems to be able to inhibit angiogenesis and metastasis by affecting the activity of Wnt signaling target genes in human PC cell lines.

CONCLUSION: Juglone has a promising potential to develop new strategies for the treatment of PC (Tab. 2,

Fig. 4, Ref. 35). Text in PDF www.elis.sk

KEY WORDS: pancreatic cancer, Wnt signaling pathway, juglone, anoikis.
\end{abstract}

\section{Introduction}

Pancreatic cancer (PC), an aggressive and malignant cancer characterized by high metastasis and angiogenesis, is one of the deadliest cancers worldwide. PC was the third leading cause of death among cancer-related diseases in the US in 2018 and its incidence and mortality rates are increasing every year. In addition to the increase in the incidence and mortality rates, the survival rates are particularly low despite all improved treatments efforts. The 5-year relative survival rate of $\mathrm{PC}$ is $8 \%(1,2)$. The lack of early specific clinical signs and symptoms of PC results in establishing the diagnosis at late stages, i.e. when metastases have already occurred (3).

The Wnt signaling pathway is one of the pathways that play an active role in many biological processes in the cell, and abnormal changes in the pathway affect the development of many cancers including PC $(4,5)$. It is well known that cell-cycle regulatory proteins and signaling pathways are important in controlling the mechanism of carcinogenesis (6). However, the contribution of the $\mathrm{Wnt} / \beta$-catenin pathway and related regulatory factors in PC deve-

Selcuk University, Faculty of Medicine, Department of Medical Biology, Konya, Turkey

Address for correspondence: F. Göktürk, Selcuk University, Faculty of Medicine, Department of Medical Biology, PK 42130, Konya, Turkey.

Phone: +90 3322244696

Acknowledgement: This study was produced from the MSc thesis of Fatma GÖKTÜRK which was supported by Instructor Training Program (2015-ÖYP-108). lopment has not been clarified yet. Thus, current studies are comprehensively focused on investigation of the association of Wnt/ $\beta$ catenin signaling activity and target genes of this pathway with PC.

Late diagnosis, high metastatic potential, and insufficiency of drugs due to chemoresistance to current drugs have led to a search for new treatment strategies in PC (3). The combinations of low-toxicity natural components with standard chemotherapeutic agents can provide additional or synergistic effects, alleviate side effects, increase uptake of conventional drugs, and support the immune system to fight against cancer. Therefore, recent studies have been focused on the investigation of anticancer properties of various phytochemicals in order to develop novel chemotherapeutic agents targeting the signaling pathways. Substances present in vegetables and fruit which have therapeutic effects have been examined intensively in the past two decades (7-10).

Juglone is a secondary metabolite that can be isolated from the leaves, roots, shells, and fruit of Juglandaceae walnut trees. Juglone has a long history in traditional Chinese treatment and has been reported to have various pharmacological effects such as antiviral, antibacterial, and antifungal effects, as well as cytotoxic effects on cancer cells (11-13). However, there is insufficient knowledge about its effects on angiogenesis, metastasis, and signal alteration on signaling pathways. Silent progression, strong invasion, and metastasis are the most challenging characteristics of PC. Thus, effective approaches to inhibit invasion and metastasis are needed. In our previous study, we showed for the first time that juglone inhibits cell invasion and metastasis in PC cell 
lines (20). Taking into account our previous work, in this current study, we aimed to analyze whether juglone shows the anticancer and antimetastatic activities over the wnt signaling by evaluating the expression levels of $T C F 7 L 2$, the key effector of the pathway, and $C C N D 1, V E G F, M M P-7$ genes which are the targets of Wnt signaling in BxPC-3 and PANC-1 human PC cell lines.

\section{Materials and Methods}

\section{Cell culture}

Human PC cell lines BxPC-3 and PANC-1 were purchased from the ATCC (Manassass, VA, USA), and cultured in RPMI1640 (Gibco, UK) and DMEM (Gibco, UK) medium supplemented with $10 \%$ FBS (Gibco, USA) and $1 \%$ penicilin/streptomycin. All the cells were cultured at $37{ }^{\circ} \mathrm{C}$ under $5 \% \mathrm{CO}_{2}$. Juglone was obtained from SigmaAldrich Chemical Company (USA).

\section{MTT assay}

MTT test was used to determine the cytotoxic effect of juglone on human PC cells. PANC-1 and BxPC-3 cells were plated in 96well plates at 5,000 cells per well in a volume of $100 \mu \mathrm{l}$ for $24 \mathrm{~h}$ before treatment. Following incubation, the media were replaced with fresh media containing various concentrations of juglone ( 0 , $5,10,15,20,30,40$ and $50 \mu \mathrm{M})$ for $24 \mathrm{~h}$, and cells were incubated at $37^{\circ} \mathrm{C}$. Twenty-four hours later, MTT solution was added to each well and incubated at $37^{\circ} \mathrm{C}$ for $4 \mathrm{~h}$. The resulting formazan crystals were dissolved with DMSO by pipetting, and the absorbance was read at $570 \mathrm{~nm}$ in an ELISA reader.

\section{Migration assay}

Migration assay was used to understand the metastatic and proliferative behavior of PC cells following juglone treatment. For this purpose, a wound-healing assay was used to quantify the cell migration. Firstly, two groups were planned as starvation and non-starvation groups. The starvation group was observed to understand the effects of juglone on metastatic behavior of PC cells while non-starvation group was evaluated to understand the effect of juglone on both metastatic and proliferative behavior of cells. For this purpose, the cells were seeded into 6-well tissue culture plates at an approximately $70-80 \%$ confluence of the wells. Cells were cultured in DMEM or RPMI 1640 medium supplemented with $10 \%$ FBS for $24 \mathrm{~h}$. A straight-line-wound was made by scraping a $200 \mu \mathrm{L}$ pipette tip across the cell monolayer. After scratching, detached cells were washed away by gently rinsing the well with PBS and cultured with appropriate medium for $48 \mathrm{~h}$ in a $5 \% \mathrm{CO}_{2}$ atmosphere at $37{ }^{\circ} \mathrm{C}$. Subsequently, the groups were treated with determined juglone concentrations. Appropriate medium with $1 \%$ FBS was used for starvation group in both cell lines. All other nonstarvation groups were supplemented with $10 \%$ FBS. The wounds were imaged at 0,24 and $48 \mathrm{~h}$ under microscopy.

\section{Gene expression analysis}

Total RNAs were extracted from the juglone-treated and control cells using TRIdity G reagent (Applichem). Reverse transcription was performed using cDNA synthesis kit (2-steps RT-PCR kit,
Tab. 1. Primers for $q P C R$ analysis of genes expression.

\begin{tabular}{|c|c|c|}
\hline Gene & Primer sequence $(\mathrm{F}, \mathrm{R})^{*}$ & Reference \\
\hline$C C N D 1$ & $\begin{array}{l}\text { F: 5'-AGCTGTGCATCTACACCGAC-3' } \\
\text { R: 5'-TGTGAGGCGGTAGTAGGACA-3' }\end{array}$ & $(30)$ \\
\hline TCF $7 L 2$ & $\begin{array}{l}\text { F: 5- TGTACCCAATCACG ACAGGA-3 } \\
\text { R: 5-GCCAGCT CGTAGTATTTCGC -3 }\end{array}$ & (31) \\
\hline$V E G F$ & $\begin{array}{l}\text { F: 5'-ATCTGCATGGTGATGTTGGA-3' } \\
\text { R: 5'-GGGCAGAATCATCACGAAGT-3' }\end{array}$ & $\begin{array}{l}(32) \\
(33)\end{array}$ \\
\hline$M M P-7$ & $\begin{array}{l}\text { F: 5'-GGATGGTAGCAGTCTAGGGATTAACT-3' } \\
\text { R: 5'-AGGTTGGATACATCACTGCATTAGG-3' }\end{array}$ & (34) \\
\hline$\beta$-aktin & $\begin{array}{l}\text { F: 5-ACTCTTCCAGCCTTCCTTC-3 } \\
\text { R: 5-ATCTCCTTCTGCATCCTGTC-3 }\end{array}$ & $(35)$ \\
\hline
\end{tabular}

*F - Forward Primer, R - Reverse Primer

RTPL12, vivantis, Malaysia). The effect of juglone on TCF7L2, $C C N D 1$, VEGF, $M M P-7$, and $\beta$-Actin (a reference gene for normalization) genes expression levels was determined using real-time PCR technique with proper primers for each gene. The primers used for PCR are presented in Table1. RT-qPCR was performed using SYBR green master mix (Thermo Scientific) at real-time PCR (Roche, LightCycler 96 Real-Time PCR Cycler). The $2^{-\triangle \Delta C T}$ method was used to analyze the relative changes in gene expressions.

\section{Statistical analysis}

Results were obtained from at least three independent experiments. The data comparison between juglone-treated and control groups were done using IBM SPSS 21.0 (SPSS Inc., Chicago, IL, USA). The univariate analysis of variance (ANOVA) was performed in groups with normal distribution, whereas KruskalWallis test was performed in groups with non-normal distribution. In all analyses, $\mathrm{p}<0.05$ was considered statistically significant.

For migration assay, the wound area was calculated using the IMAGEJ software. The area comparison between the starved group and non-starved group was done by imaging cells at 0,24 and 48 h. Kruskal-Wallis nonparametric test was used to statistically analyze the gap closures to evaluate the migration rate.

\section{Results}

\section{Effect of juglone on cell viability}

The effect of juglone on cell viability for BxPC-3 and PANC1 cell lines was determined by MTT assay. IC50 values for 24 hours were found to be 21.05 in BxPC-3 cells and $21.25 \mu \mathrm{M}$ in PANC-1 cells using GraphPad Prism 6. Based on IC50 values; 5 $\mu \mathrm{M}, 10 \mu \mathrm{M}, 15 \mu \mathrm{M}$ and $20 \mu \mathrm{M}$ juglone doses were determined as treatment doses in our study.

\section{Effect of juglone on Wht target genes expressions}

After juglone treatments, Wnt target genes TCF7L2, CCND1, $V E G F$, and $M M P-7$ expressions were determined using RT-qPCR analysis. After 24-h juglone treatment in $\mathrm{BxPC}-3$ cell line, the gene expressions were compared to those of the control group; for TCF7L2 gene 1.57-, 1.62-, 1.70-, and 1.03-fold decreases were detected at $5 \mu \mathrm{M}, 10 \mu \mathrm{M}, 15 \mu \mathrm{M}$, and $20 \mu \mathrm{M}$ juglone doses, respectively. Of these doses, the decreases at $10 \mu \mathrm{M}$ and $20 \mu \mathrm{M}$ juglone treatments were found statistically significant $(\mathrm{p}<0.05)$. 


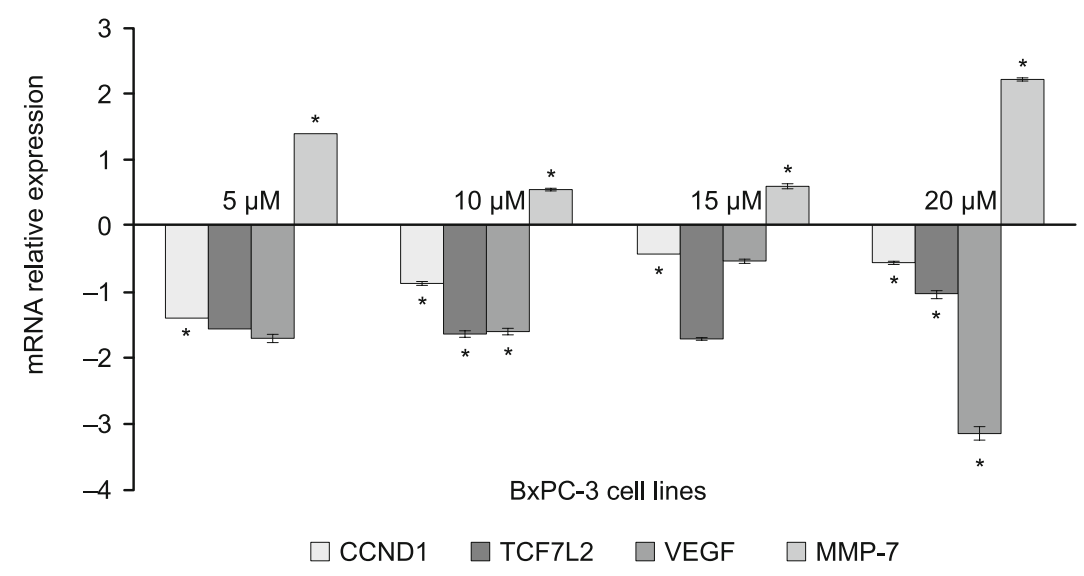

Fig. 1. Effects of juglone on expression of CCND1, TCF7L2, VEGF and MMP-7 genes in BxPC-3 cells for $24 \mathrm{~h}$ determined by the RT-qPCR analysis. Values represent the mean $\pm \mathrm{SD}$ in three independent experiments. * is used to show statistical significance $(p<0.05)$.

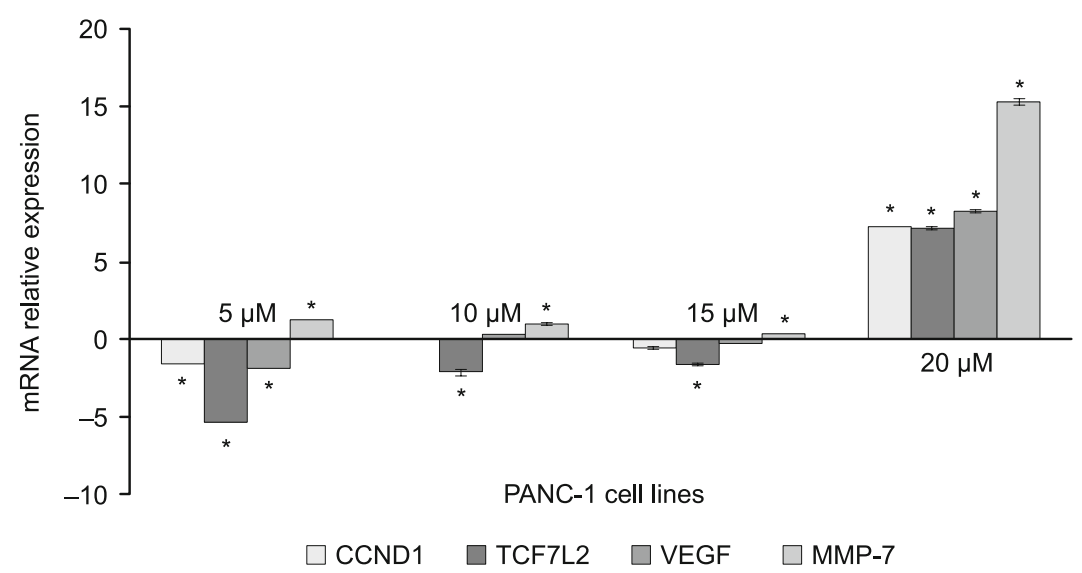

Fig. 2. Effects of juglone on expression of CCND1, TCF7L2, VEGF and MMP-7 genes in PANC-1 cells for $\mathbf{2 4} \mathrm{h}$ determined by the RT-qPCR analysis. Values represent the mean $\pm \mathrm{SD}$ in three independent experiments. * is used to show statistical significance $(p<0.05)$.

determined a 7,22-fold increase, namely at $20 \mu \mathrm{M}$ juglone treatment to be statistically significant when compared to the control group ( $\mathrm{p}<0.05)$. For $C C N D 1$ gene expression, 1.70 - and 0.65 -fold decreases were determined at $5 \mu \mathrm{M}$ and $15 \mu \mathrm{M}$ juglone doses, respectively. The expression decrease at $5 \mu \mathrm{M}$ dose was statistically significant $(\mathrm{p}=$ 0.014 ) while the decrease at $15 \mu \mathrm{M}$ juglone dose was not $(\mathrm{p}>0.05)$. On the other hand, 0.09-and 7.3-fold increases were determined at $10 \mu \mathrm{M}$ and $20 \mu \mathrm{M}$ concentrations for the expression level of CCND1. The increase at $20 \mu \mathrm{M}$ juglone dose was found statistically significant $(\mathrm{p}=0.001)$. For $V E G F$ gene expression, 1.99-, and 0.35-fold decreases at $5 \mu \mathrm{M}$ and $15 \mu \mathrm{M}$ treatment doses, and 0.20 - and 8.24-fold increase at $10 \mu \mathrm{M}$ and $20 \mu \mathrm{M}$ juglone doses were determined. Among these doses, the 1.99-fold decrease and 8.24-fold increase were statistically significant at $5 \mu \mathrm{M}$, and $20 \mu \mathrm{M}$ in juglone-treated groups $(\mathrm{p}<0.05)$. Finally, 1.24-, 0.95-, 0.33 -, and 15.30-fold increases were determined as statistically significant $(\mathrm{p}<0.05)$ for $M M P-7$ gene expression at $5 \mu \mathrm{M}, 10$ $\mu \mathrm{M}, 15 \mu \mathrm{M}$ and $20 \mu \mathrm{M}$ juglone concentrations. The effects of juglone on expression of CCND1, TCF 7L2, VEGF and MMP-7 genes in PANC-1 cells are shown at Figure 2.

\section{Effects of juglone on migration assay}

According to the evaluation under microscope, after 24-h and 48-h juglone treatments of the cells, in parallel with the increase in the dose of juglone, the gaps were observed to expand (by 5 to $20 \mu \mathrm{M}$ ). The

For $C C N D 1$ gene, at $5 \mu \mathrm{M}, 10 \mu \mathrm{M}, 15 \mu \mathrm{M}$ and $20 \mu \mathrm{M}$ juglone treatments 1.43-, 0.87-, 0.46-, and 0.57-fold decreases were detected, respectively. The decreases detected at all juglone doses used in the study were determined to be statistically significant as compared to the control group $(\mathrm{p}<0.05)$. The $V E G F$ gene expression levels decreased by 1.7-, 1.62-, 0.50-, and 3.17-fold at $5 \mu \mathrm{M}, 10$ $\mu \mathrm{M}, 15 \mu \mathrm{M}$, and $20 \mu \mathrm{M}$ juglone doses as compared to the control group. The decreases in $V E G F$ gene expression at $10 \mu \mathrm{M}$ and 20 $\mu \mathrm{M}$ treatment groups were statistically significant compared to the control group $(\mathrm{p}<0.05)$. For $M M P-7$ gene, 1.40-, 0.56-, 0.6- and 2.2-fold increases were determined at $5 \mu \mathrm{M}, 10 \mu \mathrm{M}, 15 \mu \mathrm{M}$, and $20 \mu \mathrm{M}$ juglone concentrations, respectively, and all were statistically significant $(\mathrm{p}<0.05)$. The effects of juglone on the expression of CCND1, TCF7L2, VEGF, and MMP-7 genes in BxPC-3 cell line are shown in Figure 1.

According to expression results in PANC-1 cell lines, juglone reduced the expression of $T C F 7 L 2$ gene significantly by 5.53-, 2.25-, and 1.69 -fold at $5 \mu \mathrm{M}, 10 \mu \mathrm{M}$ and $15 \mu \mathrm{M}$ doses $(\mathrm{p}<0.05)$ but we wound closure was expressed as the remaining area uncovered by the cells. The closures of gaps areas were different at each juglone concentration. The juglone treatment reduced migration in all starved and non-starved groups of BxPC-3 and PANC-1 cells as compared to the wound closure of control groups. The smallest wound closure rate was observed in $20 \mu \mathrm{M}$ juglone treatment groups as shown in Figures 3 and 4 in both starved and non-starved groups of BxPC-3 and PANC-1 cell lines with naked eye as compared to other treated groups. However, according to statistical evaluation of comparisons, the differences were not statistically significant $(\mathrm{p}>0.05)$, possibly because of insufficient sample quantity. Wound-healing levels are expressed as percentage in Table 2.

\section{Discussion}

Cancer is one of the most stringent health problems that threaten human life in the 21 st century and dramatically reduce its quality. A great deal of effort has been made in several multidis- 
BxPC-3 starvated cells

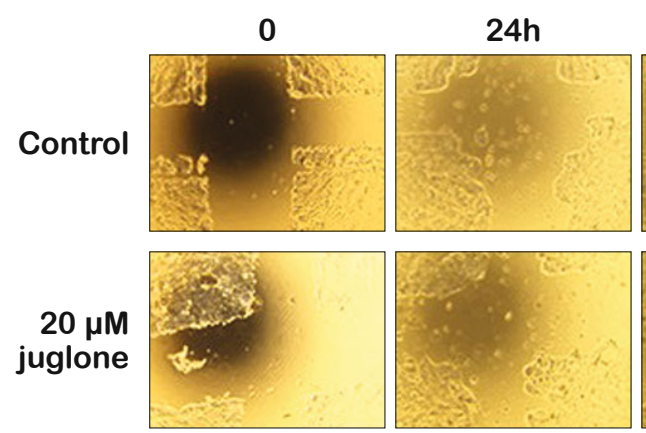

$48 h$
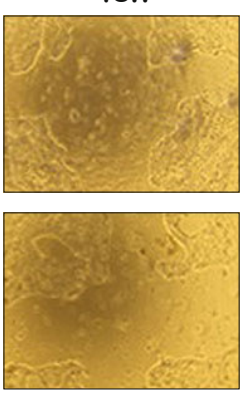

BxPC-3 non-starvated cells

0

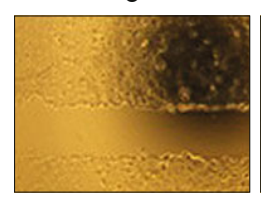

$24 \mathrm{~h}$
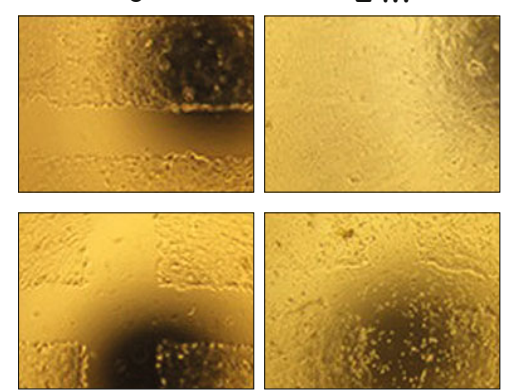

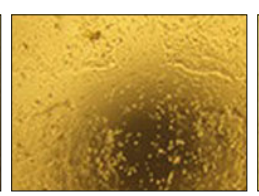

$48 \mathrm{~h}$
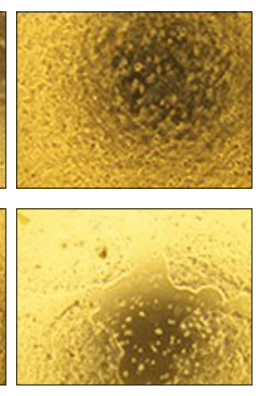

Fig. 3. Microscopic images capturing each time point in the $20 \mu \mathrm{M}$ juglone treatment and control groups in BxPC-3 cell line.

PANC-1 starvated cells
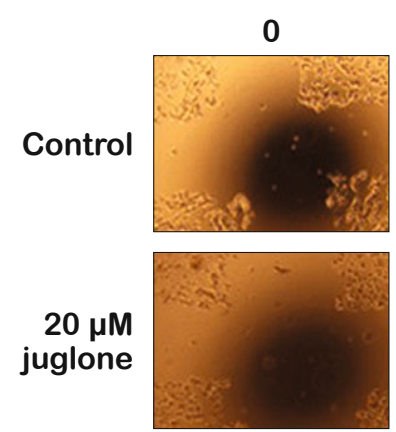

$24 \mathrm{~h}$
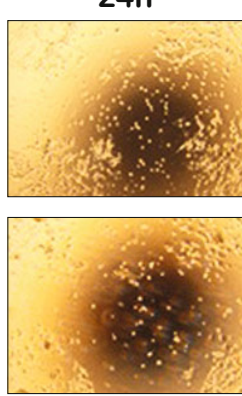
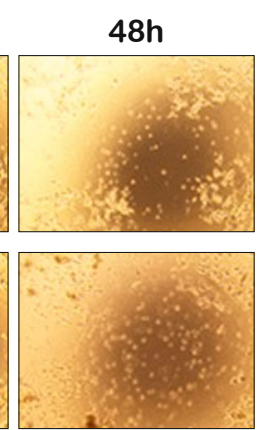

PANC-1 non-starvated cells
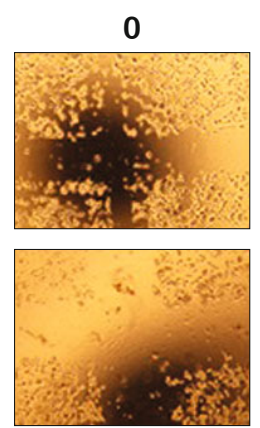

$24 \mathrm{~h}$
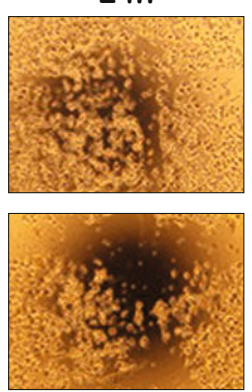

$48 h$
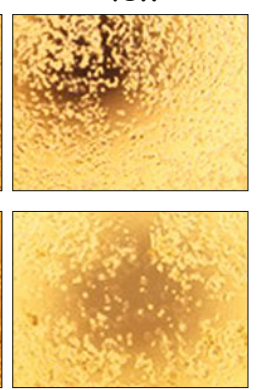

Fig. 4. Microscopic images capturing each time point in the $20 \mu \mathrm{M}$ juglone treatment and control groups in PANC-1 cell line.

ciplinary studies for cancer treatment in an endeavor to eliminate the negative effects on human life. PC has the highest mortality rates among the top five cancer types in this challenging combat. Current treatment options are inadequate and cannot meet the targeted success due to poor prognosis, late diagnosis, and positional incompatibility of the pancreatic organ for surgical interventions $(2,14)$. These necessitates the development of drugs used in the current treatment, production of new drugs and strategies, and investigation of new therapeutic interventions to increase the effectiveness of systemic treatments.

Gemcitabine is the only chemotherapy agent used in the current and standard treatments of PC. It was reported that although gemcitabine inhibited temporarily but significantly the tumor

Tab. 2. Migration (wound-healing) levels for $20 \mu \mathrm{M}$ dose juglone treatments expressed as percentage.

\begin{tabular}{lllllll}
\hline \multirow{2}{*}{ Cell lines } & \multirow{2}{*}{ Concentrations } & \multicolumn{2}{c}{ Starved $^{\mathrm{a}}$} & & \multicolumn{2}{c}{ Non-starved $^{\mathrm{b}}$} \\
\cline { 3 - 4 } \cline { 6 - 7 } & & $24 \mathrm{~h}^{\mathrm{c}}$ & $48 \mathrm{~h}^{\mathrm{c}}$ & & $24 \mathrm{~h}^{\mathrm{c}}$ & $48 \mathrm{~h}^{\mathrm{c}}$ \\
\hline BxPC-3 & control & $29 \%$ & $38 \%$ & & $82 \%$ & $96 \%$ \\
cell lines & $20 \mu \mathrm{M}$ juglone & $17 \%$ & $25 \%$ & & $45 \%$ & $69 \%$ \\
\hline PANC-1 & \multirow{2}{*}{ control } & $23 \%$ & $34 \%$ & & $40 \%$ & $83 \%$ \\
Cell lines & $20 \mu \mathrm{M}$ juglone & $12 \%$ & $24 \%$ & & $10 \%$ & $19 \%$
\end{tabular}

a Starved: Appropriate medium with $1 \%$ FBS

${ }^{\mathrm{b}}$ Non-starved: Appropriate medium with $10 \%$ FBS

${ }^{c}$ Wound closure rates were calculated by comparing remaining areas after $24 \mathrm{~h}$ and $48 \mathrm{~h}$ and expressed as growth by reducing the cancer-induced stromal tissue, its usage was not effective enough to treat cancer alone (15). It was pointed out that a combined usage of gemcitabine with nab-paclitaxel relatively increased PC survival rate compared to the gemcitabine administration alone (16).

The components of plants and mushrooms may have additional or synergistic effects. When used in combination with standard chemotherapeutic agents, they may appease drug side effects and increase the access of chemotherapy drugs to cancer cells. In recent years, herbal products with low cytotoxic effects have been investigated intensively to demonstrate their potential anticancer effect on cancer cells by different mechanisms such as apoptosis stimulation or carcinogenesis prevention $(7-10,17,18)$.

In our study, we evaluated the antimetastatic and antiangiogenic effects of juglone on BxPC-3 and PANC-1 human PC cell lines. Several studies have reported that juglone showed activity against different cancer cells such as breast cancer, gastric cancer, leukemia, colon carcinoma and prostate cancer especially by inducing apoptosis in a dose-dependent manner (11-13, 19). Ji et al (11) reported that juglone has apoptotic effects on juglone-exposed human breast cancer cell line which exhibited a significant elevation in intracellular ROS level, decrease in mitochondrial membrane potential and increase in intracellular $\mathrm{Ca}(2+)$ concentration. Juglone may be viewed as an effective anticancer agent in PC because it inhibits the cell invasion and metastasis in PC cell 
lines (20). Functional abnormalities that may occur in cell signaling pathways which regulate the fate, survival, proliferation, differentiation, and function of cells are effective in the development of cellular abnormalities, cancer, and characteristic features of cancer cells. Examination on Notch signaling pathway in SKBR3 breast cancer cell line and ROS-p38 pathway in SHG62 and SHG66 glioblastoma primary cells showed that juglone might serve as a potential chemotherapeutic agent by suppressing cell proliferation through these pathways $(21,22)$.

The Wnt signaling pathway has an important role in cancer progression, angiogenesis and metastasis through changes in inner components or membrane-bound and extracellular components of the pathway. It activates/inhibits gene expression through changing the activity of complexes between DNA-binding T-cell factors (TCFs) and causes the development and progression of many cancer types (23). Thus, Wnt signaling pathway is a therapeutic target for human diseases because it plays a central role in the development of cancer. Many small molecules and biological compounds that inhibit, block, or somehow affect the Wnt pathway are being developed, and therapeutic agents are being investigated (24).

Except for the study of Avci et al (20), studies investigating the antimetastatic and antiangiogenic effects of juglone in $\mathrm{PC}$ are limited in literature. In this study, for the first time, the anticancer activities of juglone on the Wnt signaling pathway activity and its relation to metastasis and angiogenesis in PANC-1 ve BxPC-3 $\mathrm{PC}$ cell lines were examined. In this sense, CCND1, TCF7L2, $V E G F$ and $M M P-7$ genes were evaluated to determine the possible anticancer, antiangiogenic and antimetastatic effects of juglone.

TCF4 mRNA, encoded by TCF7L2 gene, is expressed at high levels in all pancreatic adenocarcinoma cell lines analyzed and additionally, the expressions of transcriptional target genes of TCF4/ $\beta$-Catenin including CCND1 and $M M P-7$ were upregulated suggesting that the increased pathway activity is caused by upregulation of direct transcriptional targets of Wnt signaling. Wnt inhibition blocked proliferation and induced apoptosis of cultured adenocarcinoma cells, thereby providing evidence in support of the development of novel therapeutical strategies for Wnt inhibition in pancreatic adenocarcinoma (25). Higher TCF7L2 expression is related to the worsening of the prognosis in $\mathrm{PC}$ patients while TCF7L2 promotes the proliferation of PC cells by positively regulating aerobic glycolysis by suppressing Egl-9 family hypoxia-inducible factor 2 (EGLN2), which leads to upregulation of hypoxia inducible factor 1 alpha subunit (HIF-1 $\alpha$ ) (26). In our study, juglone treatment caused a statistically significant decrease in TCF7L2 gene expression level in BxPC-3 and PANC-1 cell lines at all juglone concentrations which was parallel to the statistically significant decrease in CCND1 gene expression level that encodes Cyclin D1 which is one of the cell cycle control component, and the transcriptional target of TCF $7 L 2$.

Angiogenesis is the formation of new vessels from existing capillaries, which is also an especially important process for tumor development and metastasis. Among many factors involved in the regulation of complex angiogenesis, VEGFA is a predominant stimulant. Continuous $V E G F$ expression through VEGFR-2 leads to the development and maintenance of a vascular network that promotes tumor growth and metastasis. Drugs targeting the $V E G F$ pathway have been studied as a single agent or in combination with chemotherapy to suppress the VEGF signaling pathway (27). The inhibition of Wnt signaling through affecting the expressions of genes such as $C C N D 1$ and $V E G F$ reduced colorectal cancer cell growth, invasion and migration and induced apoptosis (28). In our study, it was concluded that juglone could be used as an anti-angiogenic agent because of the statistically significant decrease determined in $V E G F$ gene expression at $5 \mu \mathrm{M}$ dose in PANC-1 and at all application doses in the BxPC-3 cell line after 24-hour juglone treatment.

$M M P-2$ and $M M P-9$ which are familiar with $M M P-7$, members of the matrix metalloproteases family, are known to play a crucial role in the invasive process of cancer metastasis. In the previous study, it was reported that juglone decreased the expression of $M M P-2$ and $M M P-9$ genes in BxPC-3 human pancreatic cancer cell line (20). The study also reported a significant decrease in the expression of the $M M P-9$ gene while no significant difference was observed in PANC-1 cells. When we evaluated MMP-7 gene expression at different dose juglon applications in our study, a statistically significant increase was detected in both the BxPC-3 and PANC-1 cell lines, which appears to be conflicting with the study by Avci et al (20) at first glance. However, taken together the statistically significant fold decreases in the expressions of the genes CCND1, TCF7L2, VEGF determined in our study, we suggest that the increase in the expressions of $M M P-7$ gene caused by juglone may create an antimetastatic effect in a different way than we anticipated. In support of this idea, Powell et al (29) have shown that the increase in expression in the $M M P-7$ gene causes a production of the membrane-bound FAS ligand and induces apoptosis as a result of binding to the FAS receptor which is a major mediator of epithelial cell apoptosis. Endothelial and epithelial cells must be in contact with the extracellular matrix to survive and proliferate. Damage in the cell-matrix linkage can trigger anoikis both in vitro and in vivo and ultimately lead to caspase-dependent apoptosis. Thus, there seems to be another possibility, namely that the increase in $M M P-7$ gene expression, responsible for the degradation of important matrix proteins such as collagen and fibronectin, may lead to tumor cell apoptosis by triggering anoikis. In our view, further studies focused on other markers involved in those mechanisms will contribute significantly to a more comprehensive evaluation of the effects of juglone on anoikis or apoptosis.

In conclusion, our results suggest that juglone can inhibit angiogenesis and metastasis by targeting the $\mathrm{Wnt} / \beta$-catenin signaling and has a promising potential to develop new strategies for the treatment of PC.

\section{Conclusions}

According to our findings, juglone, a phytochemical compound, can inhibit the proliferation of cancerous cells, shows antimetastatic and anti-angiogenic effects by altering the expressions of the transcription factor TCF $7 L 2$ which plays a critical role in Wnt signaling pathway and transcriptional target genes CCND1, $M M P-7$ and $V E G F$, and thus can be suggested as an effective anticancer agent in fight against pancreatic cancer. 
Our study is a preliminary step to evaluate the activity of juglone against pancreatic cancer through the Wnt signaling pathway. Further comprehensive studies are needed to determine the most effective concentration of juglone and to clear out how it affects the Wnt signaling activity.

\section{References}

1. Howlader N, Noone A, Krapcho M et al. SEER Cancer Statistics Review, 1975-2014. National Cancer Institute, 2016.

2. ACS. Cancer Facts \& Figures 2018, Atlanta, Ga: American Cancer Society, 2018.

3. Massagué J, Obenauf AC. Metastatic Colonization. Nature 2016; 529 : 298-306.

4. Kim W, Kim M, Jho EH. Wnt/ $\beta$-catenin signalling: from plasma membrane to nucleus. Biochem J 2013; 450: 9-21.

5. Lesko AC, Goss KH, Prosperi JR. Exploiting APC function as a novel cancer therapy. Curr Drug Targets 2014; 15: 90-102.

6. Malladi S, Macalinao DG, Jin X et al. Metastatic Latency and Immune Evasion through Autocrine Inhibition of WNT. Cell 2016; 165: 45-60.

7. Li Q, Wang Y, Zhang L et al. Naringenin exerts anti-angiogenic effects in human endothelial cells: Involvement of ERR $\alpha / \mathrm{VEGF} / \mathrm{KDR}$ signaling pathway. Fitoterapia 2016; 111: 78-86.

8. Amin ARMR, Kucuk O, Khuri FR, Shin DM. Perspectives for Cancer Prevention with Natural Compounds. J Clin Oncol 2009; 27: 2712-2725.

9. Wang DD, Wu QX, Pan WJ, Hussain S, Mehmood S, Chen Y. A novel polysaccharide from the Sarcodon aspratus triggers apoptosis in Hela cells via induction of mitochondrial dysfunction. Food Nutr Res 2018; 62 : 10.29219/fnr.v62.1285.

10. Angst E, Park JL, Moro A et al. The flavonoid quercetin inhibits pancreatic cancer growth in vitro and in vivo. Pancreas 2013; 42: 223-229.

11. Ji YB, Xin GS, Qu ZY, Zou X, Yu M. Mechanism of juglone-induced apoptosis of MCF-7 cells by the mitochondrial pathway. Genet Mol Res 2016; 15: (3).

12. Xu HL, Yu XF, Qu SC et al. Anti-proliferative effect of Juglone from Juglans mandshurica Maxim on human leukemia cell HL-60 by inducing apoptosis through the mitochondria-dependent pathway. Eur J Pharmacol 2010; 645: (1-3) 14-22.

13. Xu HL, Yu XF, Qu SC, Qu XR, Jiang YF, Sui DY. Juglone, from Juglans mandshruica Maxim, inhibits growth and induces apoptosis in human leukemia cell HL-60 through a reactive oxygen species-dependent mechanism. Food Chem Toxicol 2012; 50 (3-4): 590-596.

14. Wolfgang CL, Herman JM, Laheru DA et al. Recent progress in pancreatic cancer. CA Cancer J Clin 2013; 63: 318-48.

15. Olive KP, Jacobetz MA, Davidson CJ et al. Inhibition of Hedgehog signaling enhances delivery of chemotherapy in a mouse model of pancreatic cancer. Science 2009; 324: 1457-1461.

16. Von Hoff DD, Ervin T, Arena FP et al. Increased survival in pancreatic cancer with nab-paclitaxel plus gemcitabine. N Engl J Med 2013; 369: 1691-1703.

17. Gajos-Michniewicz A, Czyz M. Modulation of WNT/beta-catenin pathway in melanoma by biologically active components derived from plants. Fitoterapia 2016; 109: 283-292.
18. Jin X, Sun J, Miao X, Liu G, Zhong D. Inhibitory effect of geraniol in combination with gemcitabine on proliferation of BXPC-3 human pancreatic cancer cells. J Int Med Res 2013; 41: 993-1001.

19. Kamei H, Koide T, Kojima T, Hashimoto Y, Hasegawa M. Inhibition of cell growth in culture by quinones. Cancer Biother Radio 1998; 13 (3): 185-188.

20. Avci E, Arikoglu H, Erkoc-Kaya D. Investigation of juglone effects on metastasis and angiogenesis in pancreatic cancer cells. Gene 2016; 588: 74-78.

21. Sajadimajd S, Yazdanparast R. Sensitizing effect of juglone is mediated by down regulation of Notch1 signaling pathway in trastuzumabresistant SKBR3 cells. Apoptosis 2017; 22: 135-144.

22. Wu J, Zhang H, Xu Y et al. Juglone induces apoptosis of tumor stemlike cells through ROS-p38 pathway in glioblastoma. BMC Neurology 2017; 17: 70 .

23. Schneider JA, Logan SK. Revisiting the role of Wnt $/ \beta$-catenin signaling in prostate cancer. Mol Cell Endocrinol 2018; 462: 3-8.

24. Clevers H, Nusse R. Wnt/beta-catenin signaling and disease. Cell 2012; 149 (6): 1192-1205.

25. Pasca di Magliano M, Biankin AV, Heiser PW et al. Common Activation of Canonical Wnt Signaling in Pancreatic Adenocarcinoma. PLoS ONE 2007; 2: e1155.

26. Xiang J, Hu Q, Qin Y et al. TCF7L2 positively regulates aerobic glycolysis via the EGLN2/HIF-1alpha axis and indicates prognosis in pancreatic cancer. Cell Death Dis 2018; 9: 321.

27. Fontanella C, Ongaro E, Bolzonello S, Guardascione M, Fasola G, Aprile G. Clinical advances in the development of novel VEGFR2 inhibitors. Ann Transl Med 2014; 2 (12): 123.

28. Niu XL, Hou JF, Li JX. The NK1 receptor antagonist NKP608 inhibits proliferation of human colorectal cancer cells via Wnt signaling pathway. Biol Res 2018; 51: 14.

29. Powell WC, Fingleton B, Wilson CL, Boothby M, Matrisian LM. The metalloproteinase matrilysin proteolytically generates active soluble Fas ligand and potentiates epithelial cell apoptosis. Curr Biol 1999; 9: 1441-1447.

30. Li X, Gong X, Chen J, Zhang J, Sun J, Guo M. miR-340 inhibits glioblastoma cell proliferation by suppressing CDK6, cyclin-D1 and cyclinD2. Biochem Biophys Res Commun 2015; 460: 670-677.

31. Khalooghi K, Hashemi S, Mehraban $\mathbf{N}$ et al. In vitro modulation of TCF7L2 gene expression in human pancreatic cells. Mol Biol Rep 2009; 36: 2329.

32. Yang SY, Yu H, Krygier JE, Wooley PH, Mott MP. High VEGF with rapid growth and early metastasis in a mouse osteosarcoma model. Sarcoma 2007; 95628.

33. Kalinski T, Krueger S, Sel S, Werner K, Ropke M, Roessner A. Differential expression of VEGF-A and angiopoietins in cartilage tumors and regulation by interleukin-1beta. Cancer 2006; 106 (9): 2028-2038.

34. Liao JC, Lee KT, You BJ et al. Raf/ERK/Nrf2 signaling pathway and MMP-7 expression involvement in the trigonelline-mediated inhibition of hepatocarcinoma cell migration. Food Nutr Res 2015; 59: 10.3402/ fnr.v59.29884

35. Hsu CC, Lin TW, Chang WW et al. Soyasaponin-I-modified invasive behavior of cancer by changing cell surface sialic acids. Gynecol Oncol 2005; 96: 415-422. 